\title{
Takotsubo Caused by Pulmonary Embolism
}

\author{
N Mahoungou Mackonia ${ }^{1,2 *}$, V Kedroff ${ }^{1}$, L Jean Jacques ${ }^{1}$, C Couderq ${ }^{1}$ and R Habbal ${ }^{2}$ \\ ${ }^{1}$ Department of Cardiology, Notre Dame de la Miséricorde Center Hospital, France \\ ${ }^{2}$ Department of Cardiology, Morocco
}

Submission: September 16, 2021; Published: October 12, 2021

*Corresponding author: Noël Maschell Mahoungou-Mackonia, Department of Cardiology ibn ROCHD University Hospital, Morocco

\begin{abstract}
Takotsubo is a transient acute coronary myocardial infarction due to a catecholaminergic discharge accounting for 1 in 36,000 adults after intense physical or psychological stress. Most often found in women over 50 years of age. Its association with pulmonary embolism is very rare.

With this in mind, we report the case of a 76-year-old female patient with poorly followed chronic obstructive pulmonary disease (COPD). She presented to the emergency department with acute respiratory distress and lipothymia. Clinical examination revealed hypoxia with SaP02 at $86 \%$ in free air, blood pressure at $120 / 80 \mathrm{mmHg}$, tachycardia at 112 beats/min. The electrocardiogram showed S1Q3, hyper-right axial deviation, complete right bundle branch block with fragmented QRS, positive AVR with a tachycardia of 125 beats/min. A thoracic angioscan was performed, showing a bilateral pulmonary embolism of segmental and sub-segmental level. Ultrasensitive troponins were highly elevated at 1530ng/l with transthoracic echocardiography showing signs of acute pulmonary heart disease associated with apical ballooning, very akinetic with hyperkinesia of the bases, LVEF $26 \%$ suggestive of takotsubo confirmed by coronary angiography coupled with ventriculography giving an amphora-like appearance with a healthy coronary. The patient was initially admitted to the intensive care unit and then to the hospital for an intermediate-high risk pulmonary embolism complicated by takotsubo. The etiological work-up of the pulmonary embolism was normal. She received apixaban, Ramipril and bisoprolol. The evolution was marked by a recovery of the bi ventricular function with an LVEF of $58 \%$ in 1 month.
\end{abstract}

Takotsubo was secondary to respiratory failure caused by pulmonary embolism through catecholaminergic discharge resulting in a redistribution of beta receptors in the myocardium.

Keywords: Pulmonary embolism; takotsubo cardiomyopathy; Myocardial infarction

Abbreviations: COPD: Followed Chronic Obstructive Pulmonary Disease; APH: Acute Pulmonary Heart Disease; CICU: Cardiovascular Intensive Care Unit; LVEF: Left Ventricle; HPA: Hypothalamic-Pituitary-Adrenal; MI: Myocardial Infarction; CPA: Acute Pulmonary Heart; ARBs: Angiotensin 2 Receptor Blockers

\section{Introduction}

First described in a Japanese medical journal in 1990 about 5 cases, by the team of Hikaru Sato et al. [1-3] Takotsubo cardiomyopathy usually presents as transient left ventricular dysfunction with apical wall motion abnormalities associated with electrocardiographic changes similar to those of acute coronary syndrome in the absence of significant coronary disease [4,5]. It usually lasts about 15 days, without mortality or severity in the acute phase, and usually occurs in postmenopausal women, with $90 \%$ of cases in women aged 67-70 years [5], accounting for about $80 \%$ of cases in women over 50 years [4]. Takotsubo syndrome accounts for approximately $1-3 \%$ of all patients worldwide, or 1 case per 36,000 adults. In the USA, it accounts for $0.02 \%$ of hospital admissions and $1-2 \%$ of coronary syndromes in FRANCE $[4,6]$. The pathophysiological mechanism of takotsubo cardiomyopathy remains unclear, and several possible theories have been put forward, such as excess catecholamines, coronary artery spasm, microvascular dysfunction and metabolic disorders [3]. However, many of these theories focus on the central role of the sympathetic nervous system which, in response to an emotional, physical or combined trigger, releases an excess of catecholamines that cause the disturbance in myocardial kinetics. The mechanism by which catecholamines cause these contraction abnormalities is currently unclear [1], let alone its relationship to pulmonary embolism or being triggered by it. It is with this in mind that we report a case of pulmonary embolism causing takotsubo.

\section{Case Report}

We report the case of a 76-year-old female patient with poorly monitored COPD. She presented to the emergency department with 


\section{Juniper Online Journal of Case Studies}

acute respiratory distress and lipothymia. The clinical examination revealed hypoxia with $\mathrm{SaPO} 2$ at $86 \%$ in the open air and $97 \%$ under oxygen at 6litre/minute, blood pressure at $120 / 80 \mathrm{mmHg}$, tachycardia at 112 beats/min. The electrocardiogram showed S1Q3, hyper-right axial deviation, complete right bundle branch block with fragmented QRS, positive AVR with a tachycardia of 125 beats/min. A thoracic angioscan was performed, showing bilateral segmental and sub-segmental pulmonary embolism. Ultrasensitive troponins were highly elevated at 1530ng/l with transthoracic echocardiography showing signs of acute pulmonary heart disease (APH) associated with apical ballooning, very akinetic with hyperkinesia of the bases, LVEF $26 \%$ suggestive of takotsubo confirmed by coronary angiography coupled with ventriculography giving an amphora-like appearance with a healthy coronary. The patient was initially admitted to the Cardiovascular Intensive Care Unit (CICU) and then to the hospital for an intermediate-high risk pulmonary embolism complicated by takotsubo. The etiological work-up of the pulmonary embolism was normal. She initially received oxygen therapy for 72 days, apixaban (Eliquis) $10 \mathrm{mg} \mathrm{x} 2 / \mathrm{dr}$ for 7 days then $5 \mathrm{mg} \mathrm{x} 2 / \mathrm{dr}$ for 6 months. Ramipril 5mg/dr, bisoprolol $2.5 \mathrm{mg} / \mathrm{dr}$. The evolution was marked by a recovery of the biventricular function at 1 month of the treatment with a LVEF at $45 \%$ in 2 weeks then at $58 \%$ in 1 month.

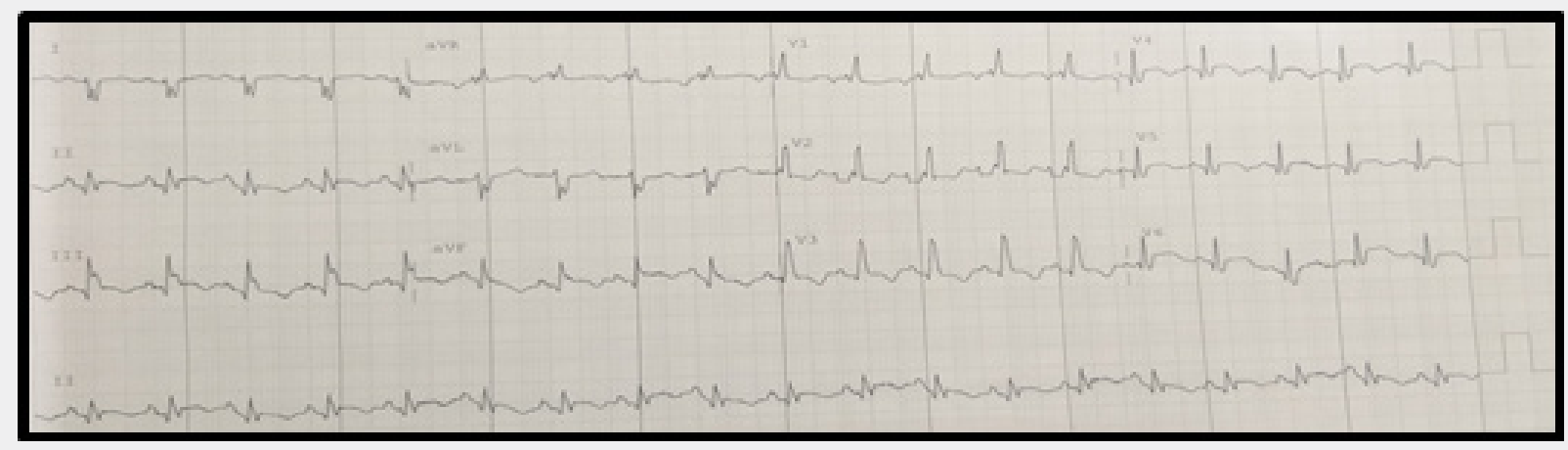

Figure 1: 12-lead ECG of a patient with high risk pulmonary embolism and Takotsubo.
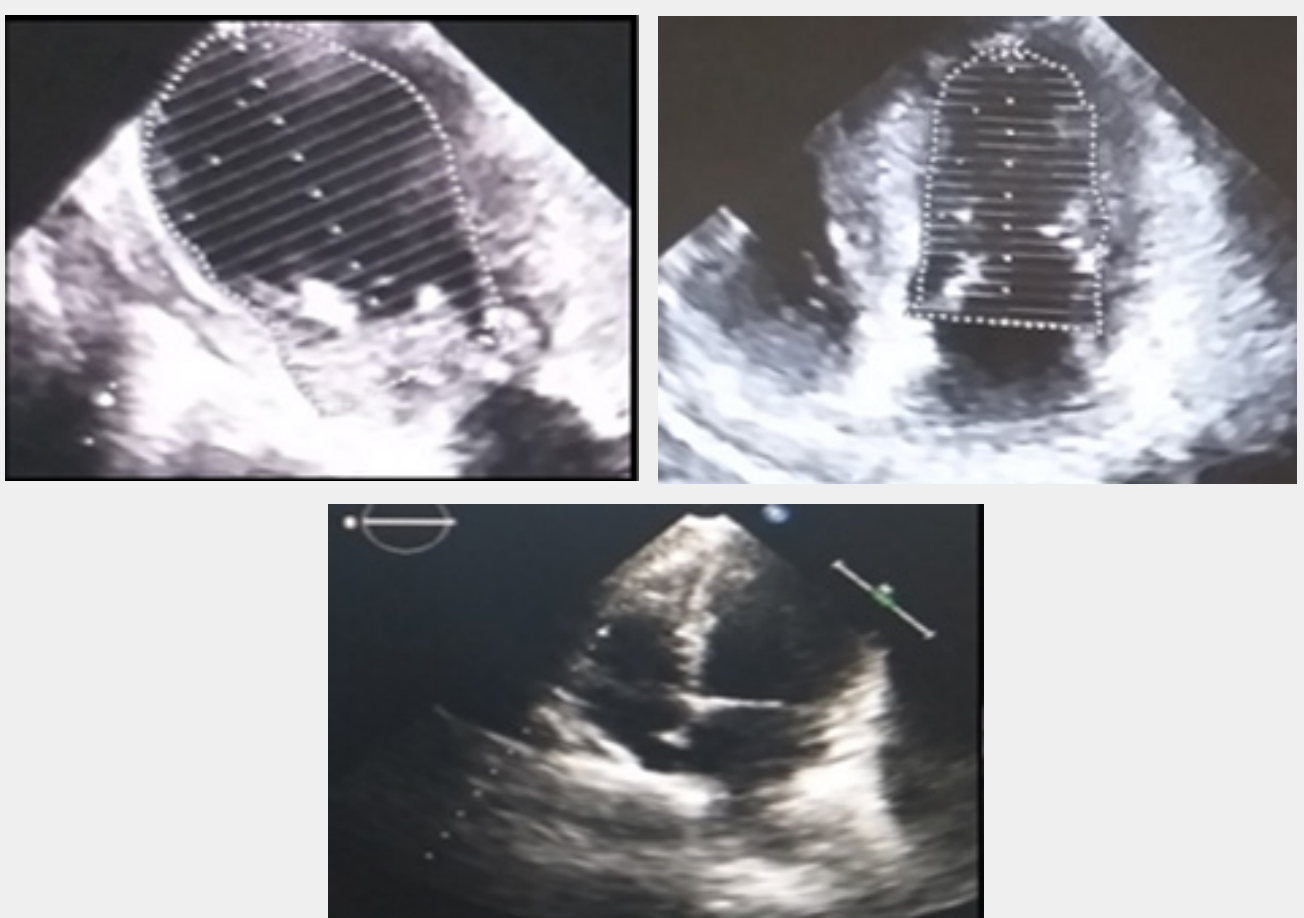

Figure 2: Right apical ballooning image with hyperkinesia of the bases LVEF26\%, recovery at 2 weeks LVEF $45 \%$ and bottom : at 1 month LVEF $58 \%$. 


\section{Juniper Online Journal of Case Studies}

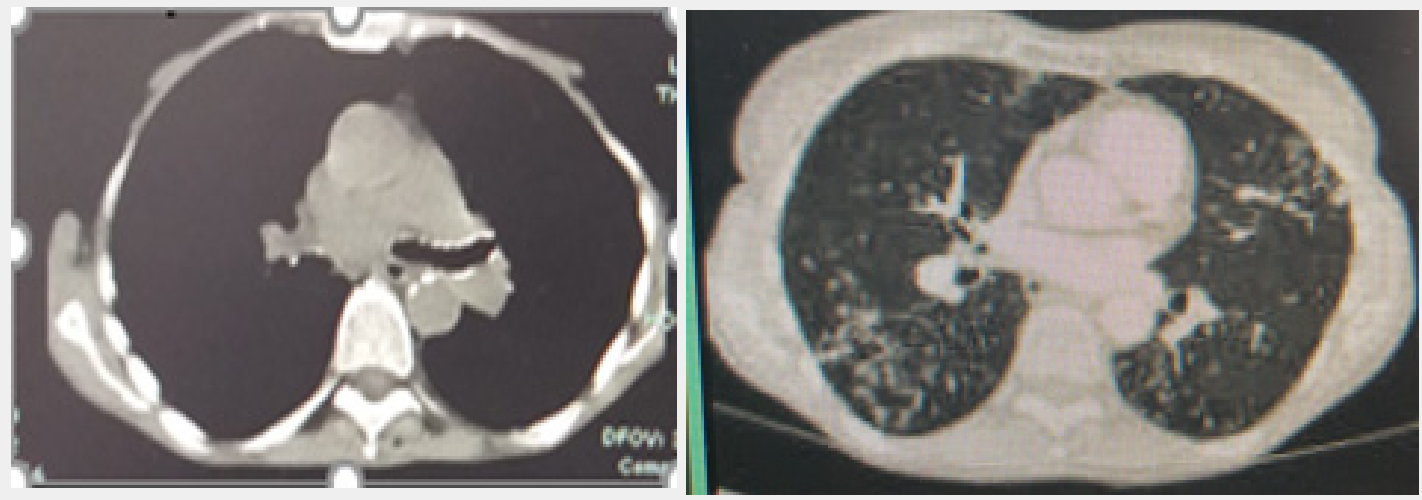

Figure 3: Thoracic angioscan showing pulmonary embolism.
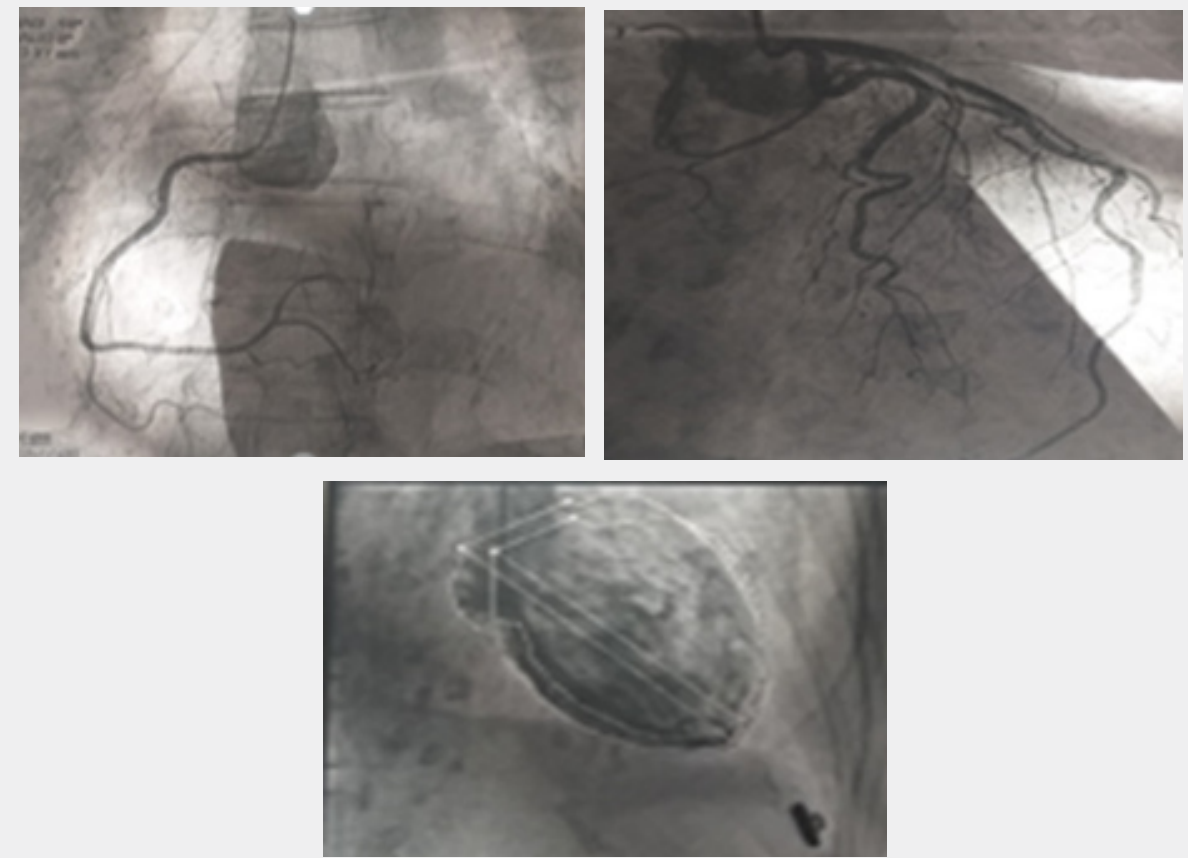

Figure 4: Normal coronary angiography with amphora appearance on ventriculography.

\section{Discussion}

Takotsubo cardiomyopathy is a transient stress cardiomyopathy, the symptomatology of which is highly suggestive of acute myocardial infarction [2]. It usually occurs in postmenopausal women and accounts for about $90 \%$ of women with a mean age of 67-70 years. A woman over 55 years of age is 5 times more likely to develop takotsubo than a younger woman, and 10 times more likely than a man [1,2]. Several factors are incriminated in the occurrence of takotsubo. Among them we have:

a) Contributing factors:

i. Falling blood levels of estradiol at the menopause (estradiol seems to protect the microcirculation from the vasoconstrictive effect of adrenaline); ii. Genetic predisposition, supported by the existence of family cases;

iii. A history of psychiatric illness observed in $42 \%$ of cases (e.g. depression in $20 \%$ of cases, anxiety) or neurological illness.

b) Triggering factors:

i. Physical stress (stroke or TIA, subarachnoid haemorrhage, acute respiratory failure, accident, strenuous sports activity, cancer chemotherapy, even coronary disorders).

ii. Negative psychological stress (bereavement, divorce, anger, anxiety, financial or professional problems, floods, earthquakes, etc.), but also positive (happy surprises) [2].

Studies that have investigated the pathophysiology of Takotsubo syndrome highlight the central role of strong 
sympathetic stimulation and parasympathetic depression [2]. Indeed, there are two initial elements of physiology to consider. The first is the cognitive centres of the brain and the hypothalamic-pituitary-adrenal (HPA) axis, and the amount of epinephrine and norepinephrine released in response to a given stress (i.e. the «gain» of the HPA axis). The second is the response of the cardiovascular system (including the myocardium, coronary arteries and peripheral vasculature) and the sympathetic nervous system to sudden sympathetic activation and the surge in circulating catecholamines. Serum catecholamine levels at presentation are significantly higher than resting levels in the same patient or in comparable patients with acute heart failure due to acute myocardial infarction (MI), suggesting a potential for excessive HPA gain and epinephrine release. However, there is currently no proven pathophysiological mechanism to clearly explain Takotsubo syndrome. There may be a synergistic combination of more than one factor, and mechanistic studies have produced conflicting results [7]. The main manifestation of takotsubo is an acute coronary syndrome characterised by angina, repolarisation disorders on the electrocardiogram with, in particular, the pathognomonic sign of an AVR lead with positive T waves, combined with the absence of negative $\mathrm{T}$ waves in the V1 lead $[3,4]$. Elevated cardiac biomarkers and kinetic disturbances are associated with severe left ventricular dysfunction such as transient akinesia or dyskinesia of the apical segments, resulting in ballooning and base preservation $[1,2,8,9]$. Coronary angiography usually finds healthy coronary arteries in $70-90 \%$ of cases, with ventriculography usually showing a characteristic amphora pattern and left ventricular wall motion abnormalities [2]. Early cardiac MRI shows global kinetic disturbances in the apical and medial segments with edematous T2 hypersignal of the apex and middle part of the left ventricle without late enhancement or perfusion abnormalities suggestive of myocarditis or infarction [10].

Pulmonary embolism is a serious and fatal condition, representing the third leading cause of death worldwide after cardiovascular disease and cancer, according to the French Federation of Cardiology in 2021 [11]. Its association with takotsubo is unclear, but increased catecholamine levels during severe pain or respiratory distress associated with pulmonary perfusion defects related to pulmonary embolism appear to lead to the development of left ventricular wall motion abnormalities [12].

Our patient is a 76 year old woman, menopausal, presenting with physical stress such as respiratory distress which constitute three factors favouring takotsubo. The diagnosis in our case was oriented by an electrocardiogram which showed a positive AVR lead although we noted an S1Q3 aspect, a hyper-right axial deviation with a complete right bundle branch block associated with repolarization disorders with fragmented QRS in favour of a pulmonary embolism. Biological markers were strongly positive and rarely encountered in pulmonary embolism. On transthoracic echocardiography, apart from the signs of CPA, we noted severe dysfunction of the left ventricle involving the apical and medial segments with apical ballooning and conservation of the bases, with diagnostic confirmation on coronary angiography coupled with ventriculography as reported in the literature, which objectified healthy coronaries with an amphoric aspect of the left ventricle. Pulmonary embolism in us being at high risk, seems to be at the origin of takotsubo, given the extent of the pulmonary artery involvement and the severity, causing respiratory failure that may be at the origin of a catecholaminergic storm. This causes a redistribution of myocardial beta receptors with a predominance of Gs forms (negative inotropes) at the apex, while G1 type beta receptors (positive inotropes) remain dense at the base. This mechanism is responsible for a dysfunction of the left ventricle with an aspect of apical ballooning in systole causing a decrease in coronary perfusion by a phenomenon of microvascular spasm, responsible for direct lesions of the myocytes as well as a metabolic disorder in the myocardium [13].

The treatment of takotsubo is mainly based on the use of ACE inhibitors and angiotensin 2 receptor blockers (ARBs) as an improvement in one-year survival has been observed with a decrease in recurrence. Whereas bêta-blockers, proposed in the therapeutic strategy, do not seem to be effective in the long term with a recurrence rate of $30 \%$. Antiplatelet agents and anticoagulants are used on a case-by-case basis in combination with treatment of the cause [1,5]. In our case, patient was treated with Ramipril, bisoprolol for takotsubo and apixaban for pulmonary embolism.

\section{Conclusion}

Pulmonary embolism associated with takotsubo cardiomyopathy is rarely described to date given its mechanism of occurrence and the severity of the two pathologies that can cause sudden death. This second entity is rarely encountered and sometimes unrecognised, and may have a poor immediate vital prognosis with rapid recovery.

\section{Consent}

In accordance with international or academic standards, the patient's written consent has been collected and retained by the author(s).

\section{References}

1. Trimaille A (2018) Tako-Tsubo syndrome: recommendation. ESC.

2. Korsia Meffre Stéphane (2018) Broken heart (takotsubo) syndrome: expert consensus published, but questions remain. European Society of Cardiology.

3. Jin Qi, Luo Q Zhao Z, Zhao Q, Yu X, et al. (2018) Takotsubo syndrome with pulmonary embolism : about a case and review of the literature. BMC Cardiovascular Disorders 18: 229.

4. Kosuge M, Ebina T, Hibi K, Tsukahara K (2012) Differences in negative $\mathrm{T}$ waves among acute coronary syndrome, acute pulmonary embolism, and Takotsubo cardiomyopathy. European Heart Journal: Acute Cardiovascular Care 1(4): 349-357. 
5. Challa S, Ganji JL, Raizada A, Najib MQ Panse PM (2011) Takotsubo cardiomyopathy in a patient with pulmonary embolism. European Journal of Echocardiography 12(10): E39.

6. Jardin, Jean-Jacques Du, et al. (2019) Takotsubo cardiomyopathy : the practitioner's journal Vol. 69.

7. Lyon AR, Bossone E, Schneider B, Sechtem U, Citro R, et al. (2015) Current state of knowledge on Takotsubo syndrome: a position statement from the taskforce on Takotsubo syndrome of the Heart Failure Association of the European Society of Cardiology. European Journal of Heart Failure 18(1): 8-27.

8. Sabrine Uhry, Charlotte Dagrenat, Haguenau (2019) Takotsubo: a rare entity : national college of hospital cardiologists.

9. Victor Y Yu, David A Leitman, Troy B Graybeal, Christian W Cox
(2011) Subsegmental pulmonary embolus as a precipitating factor for takotsubo cardiomyopathy. Radiol Case Rep 6(3): 531.

10. Dr Antoine Micheau. Arnaud de Villeneuve. University Hospital: s.n. Tako-tsubo syndrome - Myocardial stunting.

11. Pr remy-jadin, chru lille (2021). Pulmonary embolism : definition and symptoms : french federation of cardiology.

12. Seung-Hyun Lee, Dong-Hyun Kim, Min-Suk Jung, Jang-Won Lee, KyungMin Nam, et al. (2013) Inverted-Takotsubo Cardiomyopathy in a Patient with Pulmonary Embolism. Korean Circulation Journal 1738-5520.

13. N Peschanski Rouen (2011) Difficult cardiological emergencies: Takotsubo syndrome: joint session of the SFMU/SFC emergency and cardiac intensive care group.
This work is licensed under Creative

Commons Attribution 4.0 License

DOI: 10.19080/JOJCS.2021.12.555846

\section{Your next submission with Juniper Publishers will reach you the below assets}

- Quality Editorial service

- Swift Peer Review

- Reprints availability

- E-prints Service

- Manuscript Podcast for convenient understanding

- Global attainment for your research

- Manuscript accessibility in different formats

( Pdf, E-pub, Full Text, Audio)

- Unceasing customer service

Track the below URL for one-step submission

https://juniperpublishers.com/online-submission.php 